\title{
NON LINEAR CONTROL OF MULTI FED INDUCTION GENERETOR BASED OFFSHORE WIND TURBINE SYSTEM
}

\author{
Keerthana, Vahini, Sahana, Mohamed Rafi \\ Department of Electrical and Electronics Engineering \\ Imayam College of Engineering, Kannanur
}

\begin{abstract}
Novel technique is used to improve the voltage ride of wind turbine system by using LVRT System. In most of the turbines sequence operation is a proper way to increase the capacity of electronic devices in PMDD wind power generation system. Direct Current Link are regulated in this system. Because it causes the ZSCC, which brings current oscillation, distortion of waveform, reduction in power, and interruption of Electromagnetic waves, and so on. This system gives a different methodology for offshore wind turbine system which are composed of the various control strategies applied to the multi- phase converter which can deal with mostly imbalanced. Apart from averagemodels of the turbine system MVF is used to compensate highly imbalance load but not affecting the static and dynamic response of the system. Based on the above topology, the schematic diagram of the proposed system is constructed. The simulated results of offshore wind turbine system will show the advantages of the proposed system and control strategies.
\end{abstract}

Key words - Wind turbine system, Novel technique, Control strategies, Multi Variable Filter

\section{INTRODUCTION}

Wind power has emerged to be one most viable renewable source of energy. From the growth of offshore wind turbine system, the rating of power wind turbine becomes large. In the PMDD wind power production system, full power converter is employed to connect generator is to line. There is very hard to transfer the enormous amount of power to the bus by using one converter. To identify and minimize the problem, non linear control for double fed induction generator the parallel is studied. In last few decades increase of main steam wind power has increased from $6 \mathrm{MW}$ in 1996 to $282.6 \mathrm{GW}$ in 2012 . When the capability of offshore wind power turbine is steady and non-varience, the electronic devices with minimum rating can be used to decrease the cost of sequence operation. sequence operation makes kit design compact to minimize the generation time and increase the applications of module. The third order harmonics of total power can be decreases enhancely by using carrier phase shift. The rating of filter can be reduced to decrease the generation cost.

Energy wastes that increase the carbon di oxide level in the surroundings, so it is the called "global warming".Wind energy is the new way of centralized electricity production. Harmonics can be eliminated through Control and Protection Switchgear or the various construction of various sides of power transformer to decrease the pollution effects to the line. vertical axis turbines are the main components of windmills. MPPT is available to track the speed of wind. Increases losses in power, decreases the efficiency of the system, and shortened the life of switching devices.

There are mostly two ways to reduce the Zero Sequence Circulating Current. This can be reduced by destroying the way of ZSCC. On the other side, it can be reduced by true control strategies. Isolation transformer is employed to destruct the route and eliminate the Zero Sequence Circulating Current. But the transformer works at the line frequency and its volume and weight are high, this may increases the production cost of energy. Hence, this topology is not suitable for the MW- level Permenant Magnet Direct Drive offshore wind turbine system. In this system with unique direct current buses is employed, which destruct the route and eliminates the Zero Sequence Circulating Current. But this methodology is only matched for generators 


\section{International Journal of Engineering Applied Sciences and Technology, 2021 \\ Vol. 6, Issue 1, ISSN No. 2455-2143, Pages 452-458 \\ Published Online May 2021 in IJEAST (http://www.ijeast.com)}

with seperate windings. When the common multi-phase generator is employed, the problem of Zero Sequence Circulating Current is very large because the line-side Zero Sequence Circulating Current and the generator-side Zero Sequence Circulating Current are connected with one another. So the application of this field is limited. Furthermore, the disconnection of direct current buses increases the system size and is non convenient for hardware construction. In also, the two direct current bus voltages must be controlled, which requires more voltage and current sensors which makes the control system difficult. But this method of control strategy is more difficult to realize sequence operation with different modules. The Zero Sequence Circulating Current is suppressed by using null vector. But it requires to change the traditional space vector PWM (SVPWM) strategy, which turns it difficult to limit and achieve its application scope.

To reduce the above stated problems, this system proposes a new methodology for offshore wind power system. The MPPT method is employed totrack the generator and compared with the grid power. According to the above research, the Zero Sequence Circulating Current controllers are designed, which depress the lineside Zero Sequence Circulating Current and the generator-side Zero Sequence Circulating Current effectively and do not enhance the module cost. The problems caused by Zero Sequence Circulating Current are current discrepancy, current waveform distortion, are overcomes and the efficiency and reliability of the topology are improved.

The proposed system of the offshore wind turbine system is shown. A suggested a compensative control strategy of LVRT enhancement for PMSG- based wind turbine when excessive power occurs during abnormal functions. The experimental and simulation results are verified by the theoretical as well as by MATLAB simulation.

\section{II.SYSTEM TOPOLOGY}

The proposed system is shown in Fig. 1. Proposed topology is to introduce a PID adaptive control when thededication of the framework is to balance the direct current link voltage against sag voltage.

The generator side converter is convert in ac to dc and grid side converter is convert from dc to ac supply. The PID control is usedto stabilize the direct current link voltage at constant to the rotor side converter.

\section{BLOCK DIAGRAM}

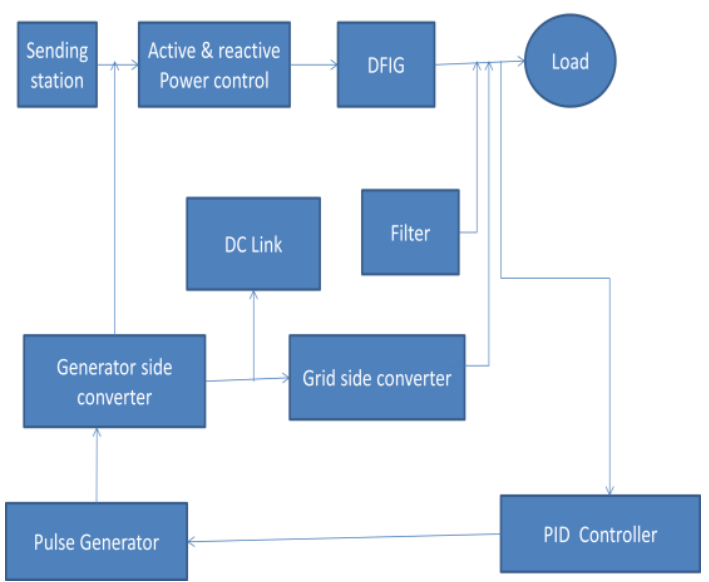

Fig 1 Block Diagram of offshore wind turbine system

Maximum power point tracking method is used to tracking the generator power. during voltage sags when the PID control to control indc link voltage and meet LVRT by reducing the generator power.

Each converteris the back-to-back two-level voltage-source converter (VSC) and n converters with the same structures are This study shows that the double fed induction generator is capable of fulfilling its role and providing the network with active power according to demand with good current quality,even in the case of an unbalanced load. $C_{k}$ is the dc bus capacitor. $L_{g k}$ is the threephase inductance of generator-side, which has the function of filtering and avoiding the shortnessof dc bus. $L_{l k}(k=1,2, \ldots, n)$ is the three-phase inductance of line-side, which can filter the harmonic, store energy, andavoid the shortness of dc bus. Increasing the inductances can suppress the high-frequency components of the ZSCCs but cannot suppress the lowfrequency components of the ZSCCs effectively. In addition, increasing inductances means the increment of volume, weight, and cost of the wind power converter. Therefore, the ZSCCs cannot be only suppressed by increasing the inductances. 


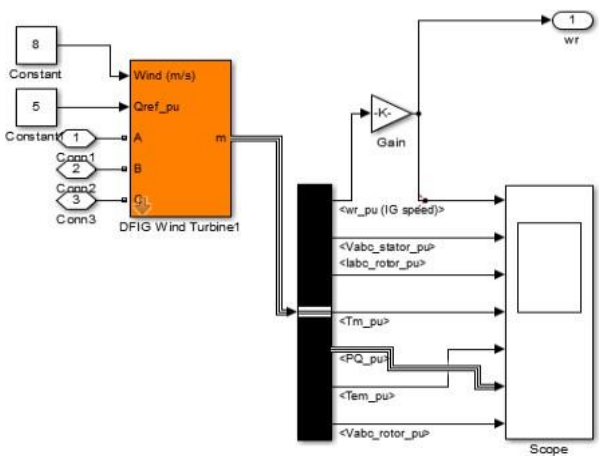

Fig 2 Model of the Wind turbine

Each converter is the second-level potential source converter and number of converters with the same structures. This study shows that the double fed induction generator which capable of complete its role and provide the system with active power based on the demand with good power quality, even in case of an imbalanced load.

\section{CONTROL STRATEGY}

Fig. 3 shows the control scheme of the offshore doubly fed induction generator wind power and Fig. 6 is the rotorcontrol scheme. The rotor angle position of the Permenant Magnet Side Generator $\theta g$ is obtained by using SMO, which has the more robust and enlarge the reliability of the system. Output of the system is given to all of the converters. The SMO is contained in the first generator-side controller. The $k$ th generatorside controller has its own Zero Sequence Circulating Current controller which function is discussed next. Behalf of the SMO and the Zero Sequence Circulating Current controllers, the remaining parts of the generator side controller have no other differences, which are given as follows.
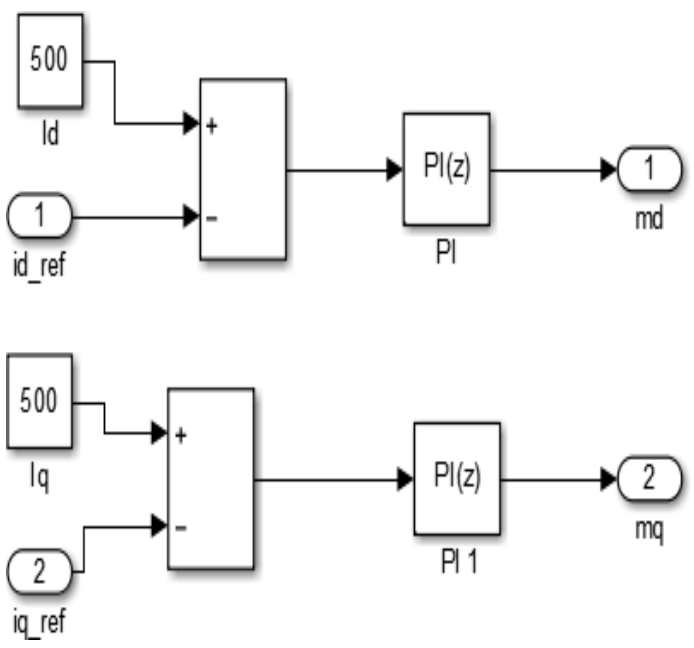

Fig 3 Current Control System of off shore wind turbine system

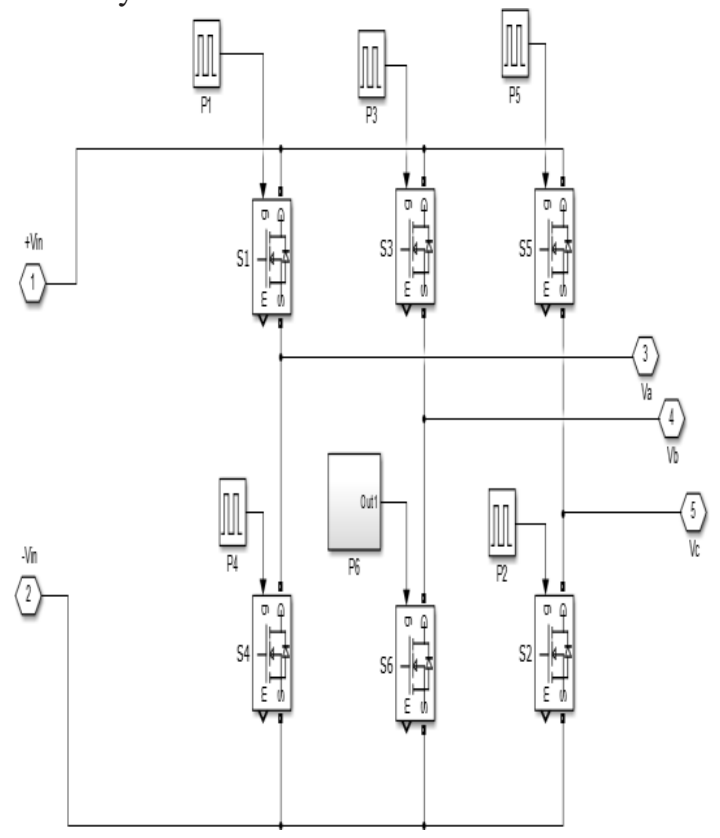

Fig 4 Control Scheme of Rotor Side Controller

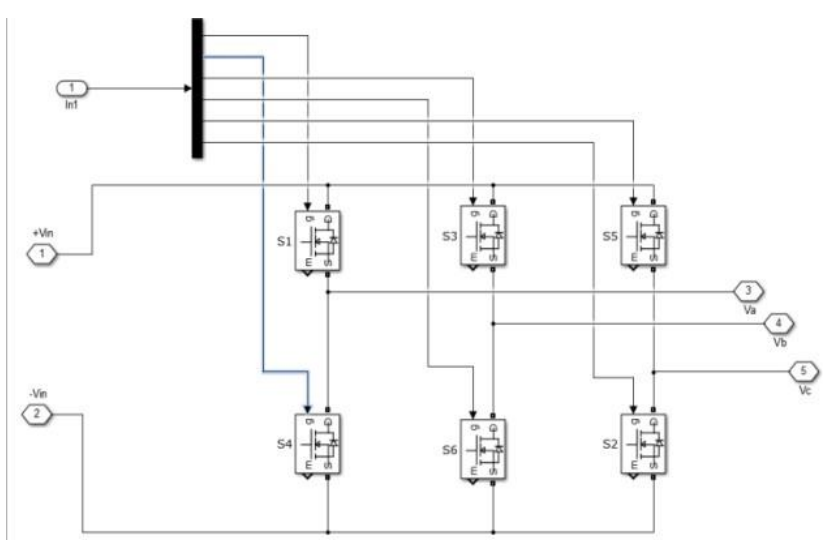

Fig 5 Control Strategy of Generator Side Converter

\section{IV.SIMULATION ANALYSIS}

This proposed system gives the MATLAB simulation of two parallel converters to verify the paramters of the proposed system and various control scheme. $n$ is assigned as two. It has been assigned by employing the simulation package The Permenant Magnet Side Generator operates at constant speed. The normal LL voltage of multi-phase grid is decreased to nominal voltage and the frequency of the grid is $50 \mathrm{~Hz}$. The Pulse Width Modulation frequency is set to around $4.9 \mathrm{kHz}$. The capacitance value of the 


\section{International Journal of Engineering Applied Sciences and Technology, 2021 \\ Vol. 6, Issue 1, ISSN No. 2455-2143, Pages 452-458 \\ Published Online May 2021 in IJEAST (http://www.ijeast.com)}

two direct current capacitors are both around $6799 \mu \mathrm{F}$ and the voltage of the direct current bus is $451 \mathrm{~V}$. To verify the characteristics of the parallel converters, some values are set manually. The inductance value of the two inductors are set as $2.1 \mathrm{mH}$ and $1.8 \mathrm{mH}$, respectively. The inductances of the line-side are set at $4.2 \mathrm{mH}$ and $3.9 \mathrm{Mh}$, respectively. The dead-time of the generator and line side converters are $2.13 \mu \mathrm{s}$ and $1.32 \mu \mathrm{s}$, respectively. Beside, the 24 Insulated Gate Bipolar Transistors used in the simulation have differences in resistance, voltage, tail time, and fall time.

Fig 6 Simulation Analysis of off shore wind turbinesystem

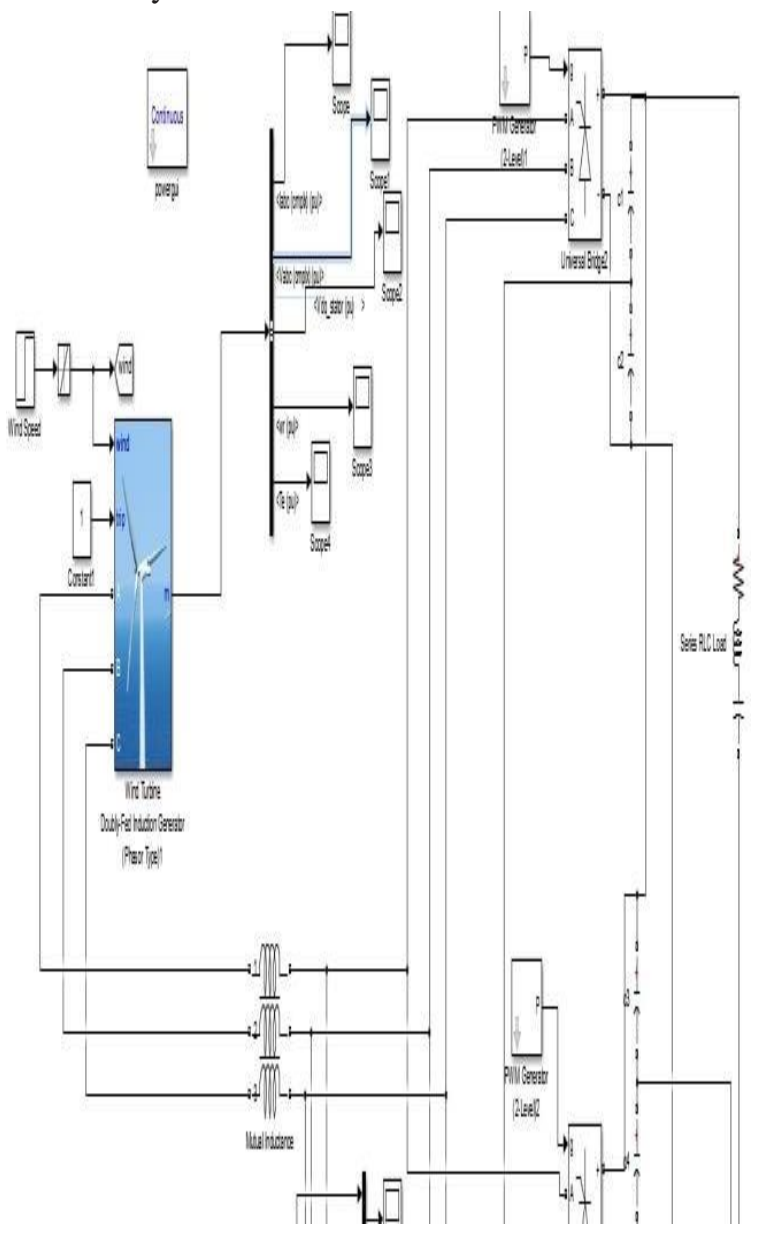

\section{EXPERIMENTAL ANALYSIS}

In addition to verify the past decades, the experiment has been conducted in a lab setup to verify the parameters of the system with the proposed methodology and the control schemes. The line-side converters and the generator-side converters are composed of two converters, respectively. In other words, $n$ is valued to two. The characteristics of the Permenant Magnet Side Generator are identical with the one in the simulation that is given in Table I. Generator-side and line side converters are connected to the Permenant Magnet Side Generator through a multi-phase inductor. The inductance of the multilevel inductor is $2,1 \mathrm{mH}$ and itsaccuracy is $9.8 \%$. The capacitances of the two direct current capacitors are valued as 6801 $\mu \mathrm{F}$ and the voltage value of the direct current bus is $451 \mathrm{~V}$. Thetwo converters are connected to the line through an inductor. The nominal inductances $3.9 \mathrm{mH}$ and its accuracy is $\pm 9.9 \%$.

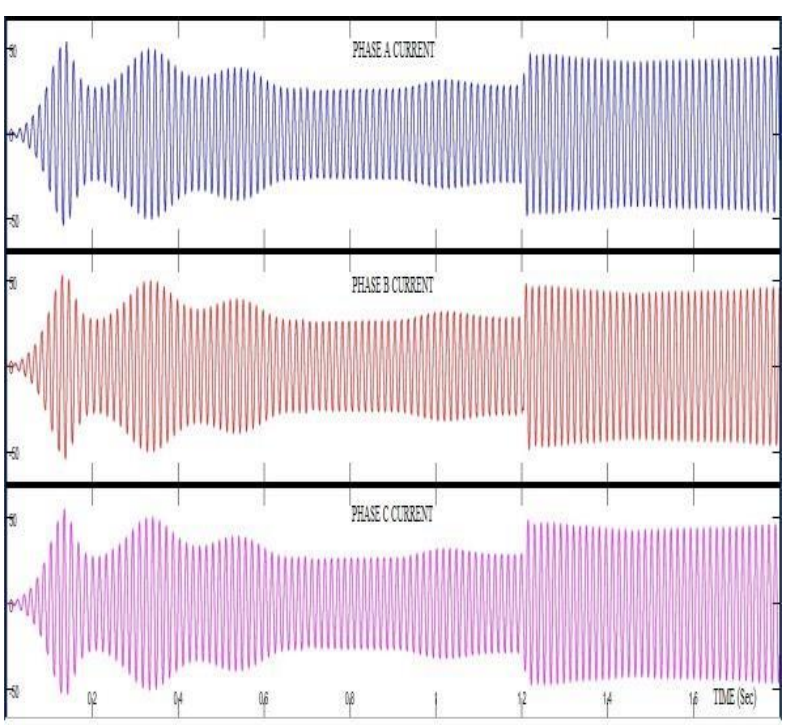

Fig 7 Output of phase current 
International Journal of Engineering Applied Sciences and Technology, 2021

Vol. 6, Issue 1, ISSN No. 2455-2143, Pages 452-458

Published Online May 2021 in IJEAST (http://www.ijeast.com)

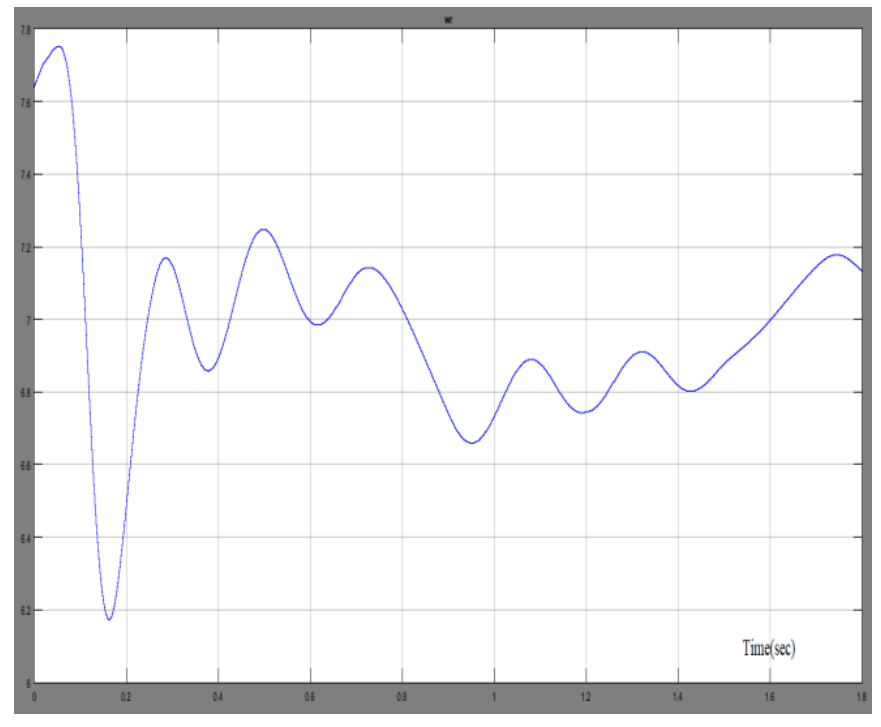

Fig 8 Output of wind turbine system

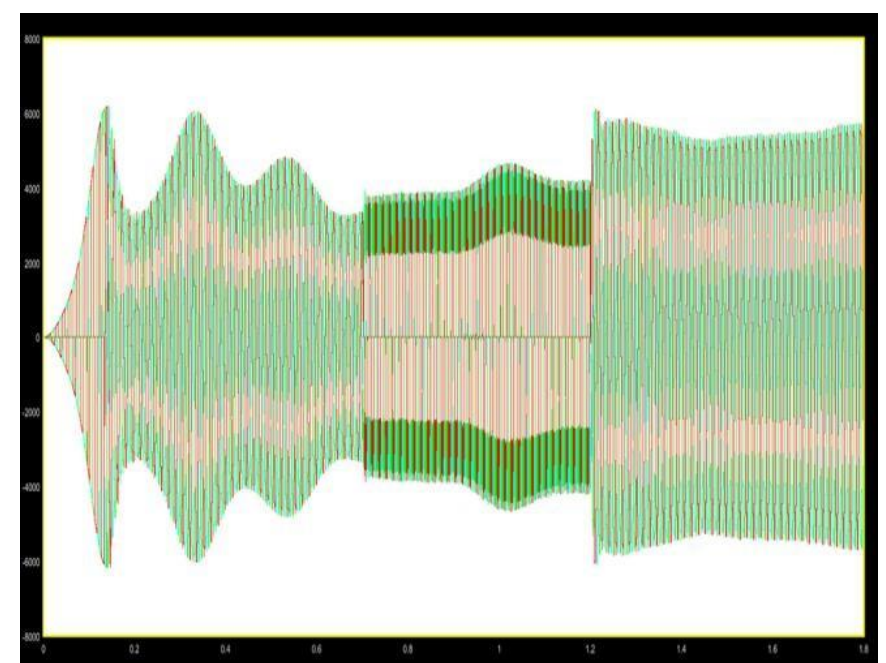

Fig 9 Output of DC Voltage system

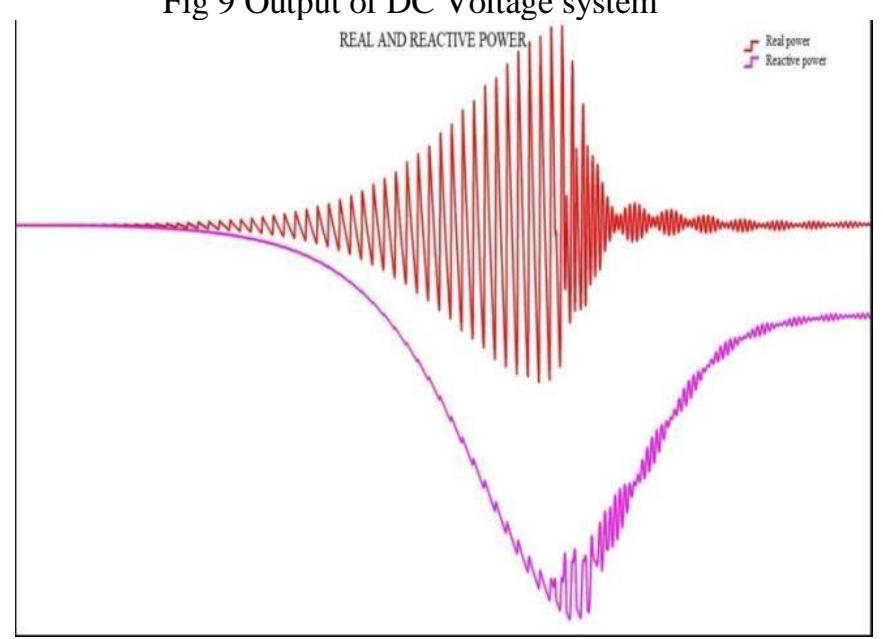

Fig 10 Output of Real and Reactive power

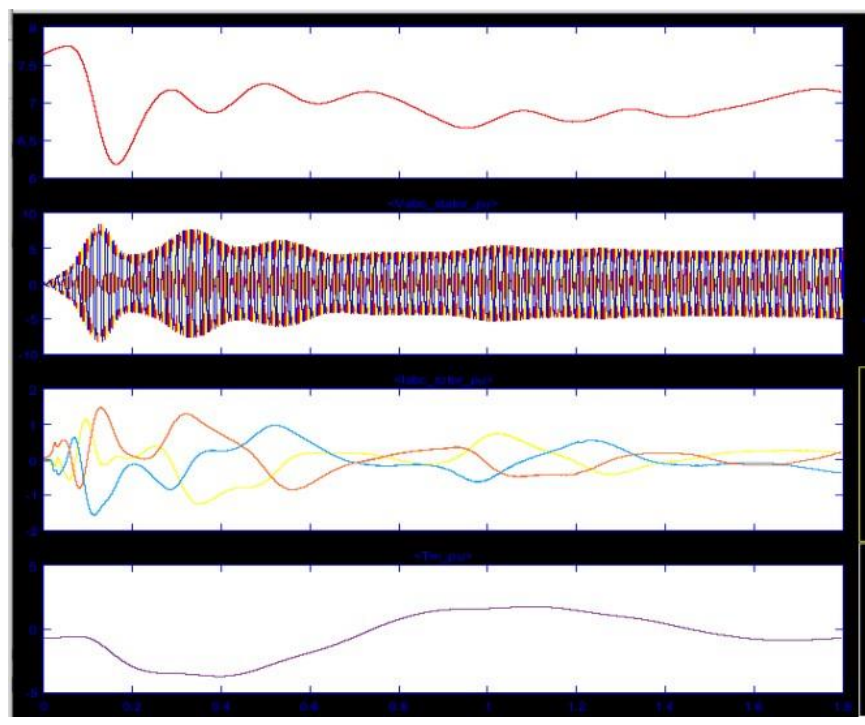

Fig 11 Output of Torque

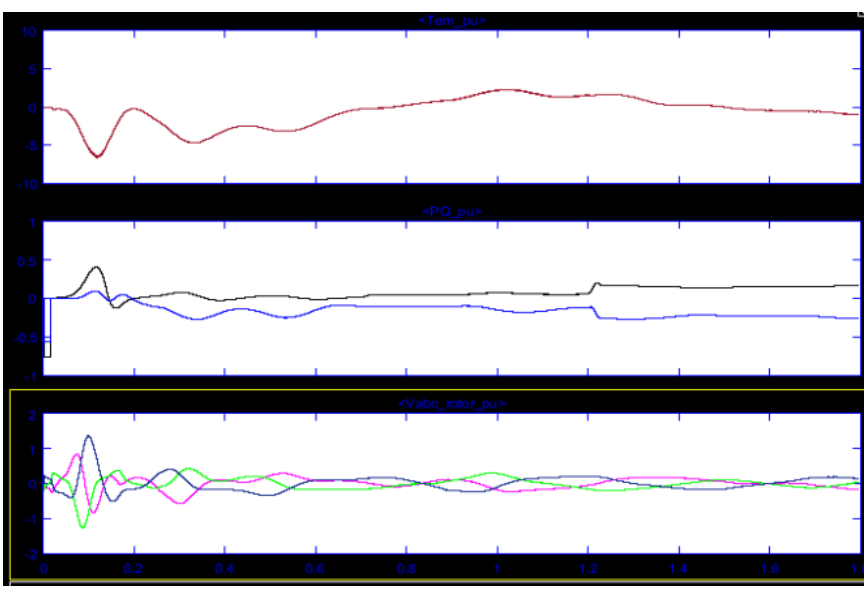

Fig 12 Output of Voltage

\section{CONCLUSION}

PMSG Non linear control unbalanced load not harmonic reduced minimum voltage produced. The proposed Zero Sequence Circulating Current controllers do not increase the module cost and they do not have no effect on the controlled variables. However, they may not modify the traditional SVPWM strategy, which turns them easier to expand and achieve their application scopes. They suppress the lineside Zero Sequence Circulating Currents and the generator-side Zero Sequence Circulating Currents effectively and the currents of converters are consistent and sinusoidal. The problems of asymmetry, current disortion, discrepancy, and are minimized well and the efficiency and reliability of the system are 


\section{International Journal of Engineering Applied Sciences and Technology, 2021 \\ Vol. 6, Issue 1, ISSN No. 2455-2143, Pages 452-458 \\ Published Online May 2021 in IJEAST (http://www.ijeast.com)}

increased. The output of this topology makes it possible to produce the wind power converters with maximum power rating. This paper studies the operation of non linear control of double fed induction generator based off shore wind turbine system. Reduced harmonics zero noise. high power produce better quality and high voltage.

\section{REFERENCES}

[1] S. Li and T. A. Haskew, "Characteristic study of vector- controlled direct driven permanent magnet synchronous generator in wind power generation," in Proc. Power Energy Soc. Gen. Meeting, Pittsburgh, PA, 2008, pp. 1-9.

[2] S. Fukuda and K. Matsushita, "A control method for parallel-connected multiple inverter systems," in Proc. Power Electron. Variable Speed Drive Conf., London, U.K.,1998, pp. 175-180.

[3] G. H. B. Foo and M. G. Rahman, "Direct torque control of an IPMsynchronous motor drive at very low speed using a sliding-mode stator flux observer," IEEE Trans. Power Electron., vol. 25, no. 4, pp. 933-942,Apr. 2010.

[4] F. J. Lin, J. C. Hwang, P. H. Chou, and Y. C. Hung, "FPGA-based intelligentcomplementary sliding-mode control for PMLSM servo-drive system," IEEE Trans. Power Electron., vol. 25, no. 10, pp. 25732587, Oct. 2010.

[5] Z. Xu, P. Y. Ge, and D. G. Xu, "High performance control of a perma- nent magnet wind power generation system using an adaptive sliding observer," in Proc. Power Electron. Drive Syst. Conf., Taipei, Taiwan, 2009, pp. 67-71.

[6] S. Z. Chen, N. C. Cheung, K. C. Wong, and $\mathrm{J}$. Wu, "Integral sliding-mode direct torque control of doubly-fed induction generators under unbalancedgrid voltage," IEEE Trans. Energy Convers., vol. 25, no. 2, pp. 356-368, Jun. 2010.

[7] Z. Xu and M. F. Rahman, "An adaptive sliding stator flux observer for a directtorque-controlled IPM

synchronous motor drive," IEEE Trans. Ind.Electron., vol. 54, no. 5, pp. 23982406, Oct. 2007.

[8] T. P. Chen, "Circulating zero-sequence current control of parallel three- phase inverters," Proc. Inst. Elect. Eng.-Elect. Power Appl., vol. 153, no. 2, pp. 282-288,
Mar. 2006.

[9] Y. Chen and K. M. Smedley, "One-cyclecontrolled three- phase grid- connected inverters and their parallel operation," IEEE Trans. Ind. Appl.,vol. 44, no. 2, pp. 663-671, Mar./Apr.2008.

[10]Z. H. Ye, D. Boroyevich, J. Y. Choi, and F. C. Lee, "Control of circulating current in two parallel three-phase boost rectifiers," IEEE Trans. Power Electron., vol. 17, no. 5, pp. 609-615, Sep. 2002.

[11] S. K. Mazumder, "Continuous and discrete variable- structure controls for parallel three-phase boost rectifier," IEEE Trans. Ind. Electron., vol. 52, no. 2, pp. 340354, Apr. 2005.

[12] R. M. Cuzner, D. J. Nowak, A. Bendre, G. Oriti, and A.

L. Julian, "Miti- gating circulating commonmode currents between parallel soft-switched drive systems," IEEE Trans. Ind. Appl., vol. 43, no. 5, pp. 1284-1294, Sep./Oct. 2007.

[13] T. P. Chen, "Dual-modulator compensation technique for parallel inverters using space-vector modulation," IEEE Trans. Ind. Electron., vol. 56, no. 8, pp. 3004-3012, Aug. 2009.

[14] F. S. Pai, J. M. Lin, and S. J. Huang, "Design of an inverter array for distributed generations with flexible capacityoperations," IEEE Trans. Ind. Electron., vol. 57, no. 12, pp. 3927-3934, Dec. 2010.

[15] R. Ramos, D. Biel, E. Fossas, and F. Guinjoan, "Interleaving quasi- sliding-mode control of parallel- connected buck-based inverters," IEEE Trans. Ind. Electron., vol. 55, no. 11, pp. 3865-3873, Nov. 2008.

[16] J. Holtz, W. Lotzkat, and K. H. Werner, "A high-power multitransistor- inverter uninterruptable power supply system," IEEE Trans. Power Electron., vol. 3, no. 3, pp. 278-285, Jul. 1988.

[17] C. T. Pan, J. Y. Chang, C. M. Lai, Y. L. Juan, and Y. H. Liao, "Modeling of circulating currents for grid-connectedparallel three-phase inverters," in Proc. SICE Annu. Conf., Tokyo, Japan, 2008, pp. 1319-1322.

[18] L. L. Chen, L. Xiao, C. Y. Gong, and Y. G. Yan, "Circulating current's characteristics analysis and the control strategy of parallel system based on double close-loop controlled VSI," in Proc. IEEE Power Electron. Spec. Conf., Aachen, Germany, 2004, pp. 47914797.

[19] Y. Chen and K. M. Smedley, "Parallel 


\section{International Journal of Engineering Applied Sciences and Technology, 2021 \\ Vol. 6, Issue 1, ISSN No. 2455-2143, Pages 452-458 \\ Published Online May 2021 in IJEAST (http://www.ijeast.com)}

operation of one- cycle controlled three-phase PFC rectifiers," IEEE Trans. Ind. Electron., vol. 54, no. 6, pp. 3217-3224, Dec. 2007.

[20] N. A. Rahim and J. Selvaraj, "Multistring five-level inverter with novel PWM control scheme for PV application," IEEE Trans. Ind. Electron., vol. 57, no. 6, pp. 2111-2123, Jun.2010.

[21] W. Yao, M. Chen, J. Matas, J. M. Guerrero, and Z. M. Qian, "Design and analysis of the droop control method for parallel inverters considering the impact of the complex impedance on the power sharing," IEEE Trans. Ind. Electron., vol. 58, no. 2, pp. 576-588, Feb. 2011.

[21] S. K. Mazumder, "A novel discrete control strategy for independent stabilization of parallel three-phase boost converters by combining space- vector modulation with variable-structure control," IEEE Trans. Power Electron., vol. 18, no. 4, pp. 10701083, Jul. 2003.

[22] C. T. Pan and Y. H. Liao, "Modeling and coordinate control of circu- lating currents in parallel three-phase boost rectifiers," IEEE Trans. Ind. Electron., vol. 54, no. 2, pp. 825-838, Apr. 2007.

[23] M. Jones, S. N. Vukosavic, and E. Levi, "Parallel- connected multiphase multidrive systems with single inverter

supply," IEEE Trans. Ind. Elec- tron., vol. 56, no. 6, pp. 2047-

2057, Jun. 2009.

[24] K. Xing, F. C. Lee, D. Borojevic, Z. H. Ye, and S. Mazumder,

"Interleaved PWM with discontinuous spacevector

modulation," IEEE Trans. EnergyConvers., vol. 14 , no. 5 , pp.

906-917, Sep. 1999.

[25] C. T. Pan and Y. H. Liao, "Modeling and control of

circulating currents for parallel three-phase boost rectifiers

with different load sharing," IEEE Trans. Ind. Electron., vol.

55, no. 7, pp. 2776-2785, Jul. 2008.

[26] J. L. Li, Z. G. Gao, S. J. Hu, X. B. Fu, and $\mathrm{H} . \mathrm{H} . \mathrm{Xu}$,

"Applicationof parallel back-to-back PWM converter on the

direct-drive wind power system," Autom. Elect. Power Syst.,

vol. 32, no. 5, pp. 59-62, Mar. 2008. 